\title{
Physical Teaching Leisure Life Mode
}

\author{
Weiqing Fan \\ School of Tourism Commerce Vocational of Jiangx University, Nanchang 330100, China.
}

673407137@qq.com

Keywords: Physical education; leisure patterns; necessity; policy

\begin{abstract}
This paper analyzes the necessity of Physical Education Life Leisure education model implemented analyzes the strategy to build the leisure life teaching mode to cultivate awareness of students' lifelong physical exercise, physical education content rich, increase physical fun, improve physical education the effect of promoting the overall development of students having a positive effect.
\end{abstract}

\section{Introduction}

As PE teachers to be able to innovative teaching philosophy, to actively pursue a harmonious democratic classroom environment, can have an inclusive attitude and equal exchanges with students can be active and innovative teaching mode, reference leisure sports teaching mode to create a relaxed and pleasant learning range, so that students can easily free initiative into motion the process to learn sports. Thus, in order to effectively enhance the effect of physical education, and promote the development of student health improvement. As PE teachers to study and leisure life teaching mode Approaches to achieve innovation through Physical Education Teaching.

\section{Necessity of Physical Education Teaching Mode leisure implemented}

Innovative education model, is the inevitable choice of Physical Education. Physical education process, it is necessary to implement the objectives of quality education through physical education not only enable students to acquire the necessary basic knowledge and sports skills, increase students' physical fitness, but also need to be able to cultivate the students' sentiments through physical education, improve students' psychological, culture students participate in lifelong physical awareness and promote literacy to enhance the students' comprehensive.

However, the current status of physical education and sports educational content model is more traditional, old-fashioned content, interest is not strong, Physical education is quite old, basically didactic teacher demonstration, the lack of innovation and education. Thus, many students are reluctant to participate in sports to learn, do not want to participate in sports, student activists is not strong, education through sport, to promote the educational objectives of the student's physical and mental health will be difficult to achieve. Thus, in physical education, we must establish a new philosophy of education, innovation and Physical Education. Student body can carry out physical education, to respect individual differences of students, to meet the psychological needs of students learning sports movement, innovative sports model, to be able to actively through the leisure life of the sports teaching mode, so that students can really fall in love with sports learning to love sports, so, in order to promote students' physical and mental development, culture can really interested in sports, to actively participate in sports students.

In addition, physical education can be directed through leisure sports teaching model students to establish a correct outlook on life and values. Students now living environment is more complex, a variety of network temptation for students a greater negative impact. Coupled with the accelerated pace of life now, student competition under great pressure. In this environment, many students choose to indulge in the online world, they escape through a network of pressure to eliminate negative emotions in real life learning, and in the online world, they can be happy, relax. In this way, the students very little time to participate in sports, and even students paid little attention to real life, which seriously affected the healthy development of the student body. Some negative information 
network for students to produce a large negative psychological impact, especially there are some elements of violence and pornography on the Internet, the negative impact on students is great. In this situation, physical education also need to be able through effective way to pull students out of the predicament, it is possible to enable students to correctly face the reality of life. To the front through education, promote student talent. The physical education to achieve this educational function, but also need the help of the leisure life of the educational model, this model has attracted enthusiastic student movement, students good habits through this mode and behavior, so that, in order to promote physical and mental health of students, in order to effectively achieve the goal of educating people of Physical Education.

\section{Construction Strategy of PE Teaching Leisure Life Mode}

\subsection{Physical education teachers to be innovative idea}

Innovative PE concept is the basis of PE teaching reform and innovation. As PE teachers should actively innovative concept of physical education, to realize that leisure education an important role model for enhancing sports teaching effectiveness, and promote students' physical and mental development. Teachers should realize that students are now relying on the traditional didactic education is difficult to play a better educational results, and only in the integration of physical education in some of the interesting elements into the element of life, can really enhance students' enthusiasm for learning sports, leisure and sports education model in Physical Education, which is interesting life stronger, able to meet the students to chase happiness, the pursuit of freedom of individual needs, therefore, to be innovative teacher education concept, actively foster the concept of leisure education to promote the development of physical education.

\subsection{Based on physical and psychological characteristics of students, build Leisure Life Education Model}

Young students thinking is not very mature, their outlook on life and values have not really formed. During this period, the student in a positive frame of mind ponder life, to think about life. They have their own understanding and the pursuit of their own personalized understanding and interpretation of the world. During this period, the students grow the same time, they are also very confused, the gap between the ideal and the reality of disappointments make them confused, they think through their own struggle to succeed, but also because of fear of failure and continue to retreat. Their pursuit of novelty, the traditional opposition boycott and so on. These are young students physical and mental development features. In physical education, teachers should recognize the student's physical and mental development of these features can be based on the case of physical and psychological characteristics of students to carry out physical education, sports and leisure constructing Life Education. Teachers through innovative leisure sports teaching mode, to enable students to think positively life, and guide students to correct understanding of society through innovation leisure education model, to stimulate students' struggle, and encourage students to meet the challenges overcome difficulties courage. For example, in physical education, teachers can arrange some challenging sports, such as rock climbing and pulley, through these challenging sport, training students to challenge themselves will and spirit. As another example, teachers can organize competitions projects undertaken basketball or table tennis competition in the fierce confrontation competition, students exploring spirit and cooperation, develop students' sense of competition and capacity. To this recreation and leisure sports education, through which rich flavor of life of teaching, so that students can experience the joy of sports, so that students in sport, develop their own strong will and indomitable quality.

3 To carry out sports club mode of education, enhance students' enthusiasm to participate in sports, to develop students awareness of lifelong sports participation

In physical education, educational activities can be carried out by the club model, innovative sports elective system. Students can select one sport where the exercise program according to their interests. Master motor skills in the club of the sport and choose teammates cooperative learning in this way have a rich theoretical knowledge of sports, improve their sports level. This club is a model 
of education in the implementation of education on the basis of the student's choice, the student has the right to choose sports projects. In this mode, the students' participation in sports can mean the individual to fully mobilize. After students choose sports, you can learn with teammates to upgrade their skills in the sport club. This mode of education can enhance students 'enthusiasm to participate in sports, at the same time, this way of teaching, students' lifelong physical exercise in consciousness can be effectively culture.

Club Model the physical education activities, openness and freedom of Physical Education can be fully demonstrated, students have freedom of choice, freedom of movement, the students involved in the project during the movement, the pressure from outside is gone, students choose their favorite project exercise that can effectively eliminate fatigue and stress movement, which is in line with physical education and leisure life of the educational requirements. This mode of education can create easy and free sports environment conducive to students in a relaxed environment, education, health, freedom of growth.

\section{4 innovative sports content teaching programs, increase sports life colors}

Traditional physical education, educational content basically a number of ball games, athletics, these projects are some of the traditional projects, the limitations of the project is very strong, more restrictive to students, students participate in these traditional sports interest is not high. The traditional sport is difficult to meet the students' psychological needs and exercise needs, in physical education, build sports teaching leisure education mode, you must be able to innovation in sports teaching programs content, capable of binding needs, recreational needs, innovation Some project content. With school elective system to provide students with a variety of sports teaching programs so that students can have a choice according to their needs, so in order to broaden the scope of education in sports, enhance students' motivation to learn the movement. For example, in physical education, schools can combine leisure life movement needs to carry out Aerobics, pulleys sports, martial arts, swimming courses, so that students can meet the different needs of the movement. Also these recreational sports is strong, can effectively mobilize the enthusiasm of the students 'movement, and the ability to cultivate awareness of students' lifelong sports. In addition, teachers can be arranged in PE teaching some life in the common sports content, the increasing interest in life sports, so that students in the process of participation in sports, leisure and entertainment feel happy. For example, teachers can shuttlecock sport and rope skipping motion introduced to physical education, this life of a strong sports can effectively active classroom atmosphere, increase the fun of sports, and technology not ask the students, many students are more willing to participate in the life of this sport to go get the joy of movement and calm your mood.

\section{Innovation in the leisure life of the moving object sports teaching guide}

In the traditional sports education, sports more traditional teaching methods, interest is not strong, form a single, this situation will restrict the development of physical education. To successfully build leisure sports teaching mode of education, it is necessary to be able to live under the guidance of sports and leisure destination, innovative sports teaching. To foster sports motivation through innovative teaching methods, to mobilize students sports enthusiasm and passion. To sports through innovative teaching methods to students more autonomous space activities and opportunities to promote the development of individualized freedom, so that students can actively hands-on, minds, moving mouth access to knowledge, the development of sports skills, so that students of sports athletic ability, independent living skills, self-learning ability development can be significantly improved.

As PE teachers should actively carry out innovative teaching methods in sport under the guidance of the leisure life of the target, for example, by theme approach, situational approach, the game of pedagogy, enlightenment and guidance teaching method, evaluation and incentive law and other means, innovative education. These methods are relatively close to the student life, are conducive to students interested in sports, sports for students to master knowledge and skills better, for the development of students' lifelong sports ideology and consciousness have a positive role in 
promoting, teachers should be able to choose suitable Physical education guide students to learn to guide students to think, explore, discover, and constantly enhance the culture of sports knowledge and skills of students, students' practical ability.

\section{Conclusion}

PE Creative Education Concept leisure education model, is an inevitable choice Physical Education. Lifestyle teaching only to make students acquire the necessary basic knowledge and sports skills, increase students' physical fitness, but also need to be able to cultivate the students' sentiments, improve students' psychological, and promote physical and mental health of students. Teachers need to combine leisure life, innovation project content, to provide students with a variety of sports teaching programs so that students have a choice according to their needs; give students more space and opportunities for independent activity, to promote the development of individualized freedom, increasing interest in life sports, leisure and entertainment feel happy. By theme approach, situational approach, the game of pedagogy, enlightenment and guidance teaching method, evaluation methods and other means to encourage cultivation firm will and indomitable quality of students, enhance the effect of physical education, to promote literacy to enhance the students' comprehensive.

Fund Project: Jiangxi College of Humanities and Social Sciences 2014 Project of the Year (TY1415)

\section{References}

[1] Chen Yuzhong. On Sports and Leisure Sports Leisure [J]. Shanghai Institute of Physical Education, 2010, 34(1): 25-28+33.

[2] Liu Chunyong.leisure sports in PEteaching reform in high school [J]. Success (Education). $2013,(24): 222$.

[3]Yin Jun.high school sports teaching problems and countermeasures[J].new curriculum (Secondary), 2014,(06): 28.

[4] Chen fuyuan.Talk about Fu-yuan School of Physical Education in the New Curriculum Innovation [J] high school, 2014, (16): 199.

[5] Cheng Nian study high school physical education and leisure life pattern [J] Contemporary Sport Science and Technology, 2015, (12): $118+120$. 